\title{
Perinatal Outcomes in Women with Extragenital Diseases
}

\author{
Agamurad A. Orazmuradov, $\mathrm{PhD}, \mathrm{ScD}^{1}$; Setonde Romeo D. Konnon, $\mathrm{PhD}^{1}$; \\ IrinaV. Savenkova ${ }^{1}$; Maya T. Khubetsova, $\mathrm{PhD}^{2}$; Olga L. Paendi, $\mathrm{PhD}^{3}$; \\ Aleksey A. Lukaev, $\mathrm{PhD}^{\wedge *}$ \\ ${ }^{1} R U D N$ University; ${ }^{2}$ Clinical Hospital № 29 n.a. N.E. Bauman of Moscow Healthcare Department; \\ ${ }^{3}$ City Polyclinic №170 of the Moscow City Health Department; ^Mytischi City Clinical Hospital \\ The Russian Federation
}

\begin{abstract}
An increase in the incidence of extragenital diseases (EGDs) in the population against the background of the rise in the birth rate actualizes the problems of pregnancy management in women with EGD. Pregnancy-induced physiological changes in the body lead to a worsening of the course of diseases that were at the stage of unsustainable compensation before pregnancy. The purpose of our study was to determine the effectiveness of hyperbaric oxygenation (HBO) in the prevention of obstetric complications in pregnant women with EGD and neonatal morbidity. The inclusion of HBO in a complex of therapeutic and prophylactic measures in pregnant women with high perinatal risk contributed to a significant reduction in premature birth and a statistically significant improvement in neonatal morbidity parameters. (International Journal of Biomedicine. 2017;7(2):115-119.)
\end{abstract}

Key Words: extragenital diseases • hyperbaric oxygenation • neonatal morbidity • perinatal risk

\section{Abbreviations}

EGDs; extragenital diseases; HBO, hyperbaric oxygenation; HIBI, hypoxic-ischemic brain injury; LBWN, low-birth-weight newborns; PL, premature labor; PB, premature birth; SMs, spontaneous miscarriages.

\section{Introduction}

Over the past 20 years there has been an increase in the prevalence of EGD in pregnant women; the same can be noted for complications of pregnancy, including chronic fetal hypoxia. ${ }^{(1)}$ According to the Federal State Statistics Service, ${ }^{(2)}$ during the period from 1990 to 2014 , the anemia rate increased from $12.1 \%$ to $32.0 \%$, urinary system diseases - from $5.9 \%$ to $17.0 \%$, arterial hypertension $(\mathrm{AH})$ - from $5.1 \%$ to $9.0 \%$. EGDs significantly increase the risk of developing various obstetric complications. ${ }^{(3)}$ In recent years, EGDs have occupied a leading position (28\%) in the structure of causes of maternal mortality in developed countries and Russia (23\%). ${ }^{(2)}$

The onset and development of pregnancy against the background of such EGDs as anemia, $\mathrm{AH}$, and chronic

"Corresponding author: Aleksey A. Lukaev, PhD. Mytishchi municipal clinical hospital, Mytishchi, Moscow Region, Russia E-mail: alekseilukaev@mail.ru pyelonephritis (ChP), occurs in conditions of angiopathy, primarily of the uterus vessels. ${ }^{(4)}$ Angiopathy contributes to the unavoidable development of placental insufficiency during all EGDs. ${ }^{(1)}$

The literature data indicate that an excessive "medication" of the gestational process leads to a decrease in adaptive resources of the mother and fetus and affects the health of children. ${ }^{(1)}$ Currently, the search for safe means and technologies, including non-medicinal products that will enable a woman to go through pregnancy and childbirth without difficulties, is especially important. Issues related to the prevention of obstetric and perinatal complications in pregnant women with EGDs are still open. Therefore, there is a need for an in-depth study of the possibilities of using nonmedicament means of influencing the mother-placenta-fetus system, including HBO, in order to reduce reproductive losses.

The purpose of our study was to determine the effectiveness of HBO courses in the prevention of obstetric complications in pregnant women with EGDs and neonatal morbidity. 


\section{Material and Methods}

The study was performed in Municipal clinical hospital \#29 named after N.E. Bauman. The study was conducted in accordance with ethical principles of the Declaration of Helsinki.

A total of 235 pregnant women were examined prospectively at 5 to 40 weeks of gestation. Depending on the presence of EGD, the women were divided into 2 groups. The main group included 191 pregnant women with EGD; the control group included 44 women with physiological pregnancy without EGD.

Depending on the nature of the EGD, the main group was divided into three subgroups: subgroup Ia comprised 88 pregnant women with anemia (code ICD-X: O99.0 - anemia complicating pregnancy, childbirth and the puerperium), subgroup $\mathrm{Ib}$ comprised 50 pregnant women with $\mathrm{AH}$ (code ICD-X: O10 - pre-existing hypertension complicating pregnancy, childbirth and the puerperium), and subgroup Ic comprised 53 pregnant women with $\mathrm{ChP}$ (code ICD-X: O23.0 - kidney infection in pregnancy). In turn, the three subgroups were divided into sub-subgroups, depending on the nature of the therapy: standard therapy (ST) or ST+HBO. All examined women with EGD belonged to a group with high perinatal risk (PR). We identified the degree of PR based on the scale developed by O.G. Frolova and E.I. Nikolaeva (1981) and modified in 2003 by V.E. Radzinsky et al. ${ }^{(5)}$ According to this modified scale, there is three level of PR: low risk $(<15$ points), moderate risk (from 15 to 20 points), and high risk ( $\geq 25$ points).

Inclusion criteria were singleton pregnancy, high PR, and voluntary informed consent to HBO. Exclusion criteria were cancer, multiple pregnancies, and the contraindications to the use of HBO.

Statistical analysis was performed using the SPSS for Windows. Baseline characteristics were summarized as frequencies and percentages for categorical variables and as mean (M) and standard error of the mean (SEM) for continuous variables. Group comparisons with respect to categorical variables are performed using chi-square tests. Multiple comparisons were performed with one-way ANOVA. A probability value of $\mathrm{P}<0.05$ was considered statistically significant.

\section{Results and Discussion}

98 women of the main group received, besides ST for EGD, the HBO sessions (excess air pressure 1.3-1.5 atm. in a pressure chamber). We used a single-system OKA-MT (Russia), equipped with air-conditioning 54-58 A and designed to conduct sessions in a high-pressure oxygen environment. The mode is one excess atmosphere. ${ }^{(6)}$ The course includes 5-7 daily sessions lasting 40 minutes each. The first course was carried out in 6-8 weeks, the second in 16-18 weeks, and the third in 22-24 weeks of pregnancy. ${ }^{(7)}$

The inclusion of HBO in a complex of therapeutic and prophylactic measures contributed to a significant reduction in PL $(\mathrm{P}<0.05)$. Thus, the PL incidence decreased 3 -fold in subgroup Ia, 2.3-fold in subgroup Ic, and 1.7-fold in subgroup Ib. Terms delivery are presented in Table 1 . The type of therapy influenced the choice of the delivery method only in subgroup Ic (Table 2). In subgroup Ic, on the background of $\mathrm{ST}+\mathrm{HBO}$, the rate of programmed births was significantly higher compared to ST: $7.7 \%$ and $17.4 \%(\mathrm{P}<0.05)$.

Table 1.

Terms delivery depending on the nature of the therapy.

\begin{tabular}{|c|c|c|c|c|c|}
\hline & $\begin{array}{l}\text { Group/ } \\
\text { Subgroup }\end{array}$ & & $\begin{array}{l}\text { Timely } \\
\text { delivery }\end{array}$ & $\begin{array}{l}\text { Premature } \\
\text { labor }\end{array}$ & $\begin{array}{c}\text { Delay } \\
\text { delivery }\end{array}$ \\
\hline & Anemin & $\begin{array}{c}\mathrm{ST} \\
(\mathrm{n}=42)\end{array}$ & $31(73.8 \%)$ & $11(26.2 \%)^{*}$ & 0 \\
\hline & Anenina & $\begin{array}{c}\mathrm{ST}+\mathrm{HBO} \\
(\mathrm{n}=46)\end{array}$ & $42(91.3 \%)$ & $4(8.7 \%)^{* *}$ & 0 \\
\hline  & & $\underset{(n=25)}{\mathrm{ST}}$ & $20(80.0 \%)$ & $5(20.0 \%)^{*}$ & 0 \\
\hline$\stackrel{\Xi}{\stackrel{\Xi}{\pi}}$ & АП & $\begin{array}{c}\mathrm{ST}+\mathrm{HBO} \\
(\mathrm{n}=25)\end{array}$ & $22(78.0 \%)$ & $3(12.0 \%)$ & 0 \\
\hline & ChD & $\begin{array}{c}\text { ST } \\
(n=26)\end{array}$ & $15(57.7 \%)$ & $11(42.3 \%)^{*}$ & 0 \\
\hline & CIII & $\begin{array}{c}\mathrm{ST}+\mathrm{HBO} \\
(\mathrm{n}=27)\end{array}$ & $22(81.5 \%)$ & $5(18.5 \%)^{*}$ & 0 \\
\hline Cont & $\begin{array}{l}\text { ol gro } \\
\mathrm{n}=44)\end{array}$ & & $40(90.9 \%)$ & $1(2.3 \%)$ & $3(6.8 \%)$ \\
\hline Total & $(n=235)$ & & $192(81.7 \%)$ & $40(17.0 \%)$ & $3(1.2 \%)$ \\
\hline
\end{tabular}

* - $P<0.05$ vs. the control group; ** $P<0.05$ between anemia subgroups.

Table 2.

The choice of the delivery method depending on the nature of the therapy.

\begin{tabular}{|c|c|c|c|c|c|}
\hline \multicolumn{3}{|c|}{$\begin{array}{l}\text { Group/ } \\
\text { Subgroup }\end{array}$} & $\begin{array}{c}\text { Spontaneous } \\
\text { labor }\end{array}$ & $\begin{array}{r}\text { Cesarean } \\
\text { delivery }\end{array}$ & $\underset{\text { births }}{\text { Programmed }}$ \\
\hline \multirow{6}{*}{  } & \multirow{2}{*}{ Anemia } & $\underset{(n=42)}{\mathrm{ST}}$ & $3(7.1 \%)^{*}$ & $33(78.6 \%)^{*}$ & $6(14.3 \%)^{*}$ \\
\hline & & $\begin{array}{c}\mathrm{ST}+\mathrm{HBO} \\
(\mathrm{n}=46)\end{array}$ & $5(10.9 \%)^{*}$ & $33(71.7 \%)^{*}$ & $8(17.4 \%)^{*}$ \\
\hline & \multirow{2}{*}{$\mathrm{AH}$} & $\begin{array}{c}\text { ST } \\
(\mathrm{n}=25)\end{array}$ & $2(8.0 \%)^{*}$ & $21(42.0 \%)^{*}$ & $4(16.0 \%)$ \\
\hline & & $\begin{array}{c}\mathrm{ST}+\mathrm{HBO} \\
(\mathrm{n}=25)\end{array}$ & $2(8.0 \%)^{*}$ & $21(42.0 \%)^{*}$ & $4(16.0 \%)$ \\
\hline & \multirow{2}{*}{$\mathrm{ChP}$} & $\begin{array}{c}\mathrm{ST} \\
(\mathrm{n}=26)\end{array}$ & $7(26.9 \%)^{*}$ & $17(65.4 \%)^{*}$ & $2(7.7 \%)$ \\
\hline & & $\begin{array}{c}\mathrm{ST}+\mathrm{HBO} \\
(\mathrm{n}=27)\end{array}$ & $5(18.5 \%)^{*}$ & $17(62.9 \%)^{*}$ & $5(18.5 \%)^{*}$ \\
\hline \multicolumn{3}{|c|}{ Control group $(n=44)$} & $42(95.4 \%)$ & $1(2.3 \%)$ & $1(2.3 \%)$ \\
\hline \multicolumn{3}{|c|}{ Total $(n=235)$} & $64(27.2 \%)$ & $143(60.8 \%)$ & $30(12.7 \%)$ \\
\hline
\end{tabular}

$*_{\text {- }} P<0.05$ vs. the control group

Maternal and perinatal mortality has not been documented in any of the subgroups. A total of 235 newborns were born. Parameters of body height and weight of newborns 
are presented in Table 3. Using ANOVA, we found differences among the subgroups in terms of weight, height, and circumference of the head and chest. In the comparison of subgroups, the Dunnett criterion was used.

\section{Table 3.}

\section{Anthropometric indicators of newborns.}



* - $P<0.05$ vs. the control group; ** $P<0.05$ - between subgroups depending on on the nature of the therapy

Thus, newborns born to mothers of subgroup Ia who received only ST were significantly less in weight, height, and circumference of the head and chest when compared with newborns born to mothers who received ST+HBO $(\mathrm{P}<0.05)$ and newborns in the control group. The data obtained were quite expected, since a significantly higher incidence of $\mathrm{PB}$ and fetal growth retardation $(\mathrm{P}<0.05)$ was noted in women of subgroup Ia, who received ST for anemia during pregnancy.

The average weight of the newborns of the subgroup Ic mothers against the background of ST was $2507 \pm 556.7 \mathrm{~g}$ compared to $3105 \pm 210.1 \mathrm{~g}(\mathrm{P}<0.05)$ against the background of $\mathrm{ST}+\mathrm{HBO}$. In pregnant women who received ST+HBO, the body weight, height, and circumference of the head and chest of the newborns were significantly higher when compared to those measurements in newborns born to mothers who received only ST $(\mathrm{P}<0.05)$. However, the analyzed anthropometric indices in both subgroups significantly lagged behind those of the control group $(\mathrm{P}<0.05)$.

Newborns born to mothers of subgroup Ib, who received $\mathrm{ST}+\mathrm{HBO}$, did not significantly differ in anthropometric parameters from children born to mothers of the control group . Moreover, in newborns born to mothers who received only ST, weight, height, and circumference of the head and chest were significantly less compared to the control group and newborns whose mothers received $\mathrm{ST}+\mathrm{HBO}(\mathrm{P}<0.05)$ during pregnancy.

First- and fifth-minute Apgar scores (AS) revealed statistically significant differences in subgroups $(\mathrm{P}<0.05)$
(Table 4). It was established that first-minute ASs in all newborns born to mothers of the main group were significantly lower compared to the control group $(\mathrm{P}<0.05)$. A similar situation was observed when assessing fifth-minute ASs. There was no statistically significant effect of $\mathrm{HBO}$ on AS in newborns born to mothers of subgroups Ia and Ib, only a tendency for AS to increase. Statistical differences were observed in newborns born to mothers of subgroup Ic compared to subgroups Ia and $\mathrm{Ib}$. Thus, in newborns born to mothers who received only ST, first- and fifth-minute ASs were significantly lower compared to newborns born to mothers who received $\mathrm{ST}+\mathrm{HBO}(6.7 \pm 1$ and $7.2 \pm 0,8$ points versus $7.5 \pm 0.7$ and $7.9 \pm 0.5$ points, respectively).

\section{Table 4.}

Apgar scores in newborns.

\begin{tabular}{|c|c|c|c|c|}
\hline \multirow{2}{*}{\multicolumn{3}{|c|}{$\begin{array}{l}\text { Group/ } \\
\text { Subgroup }\end{array}$}} & \multicolumn{2}{|c|}{ AS } \\
\hline & & & \multirow{2}{*}{$\begin{array}{c}\text { First-minute } \\
7.2+0.6^{*}\end{array}$} & \multirow{2}{*}{$\begin{array}{r}\text { Fifth-minute } \\
7.4+0.4^{*}\end{array}$} \\
\hline \multirow{6}{*}{ 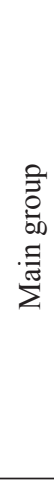 } & \multirow{2}{*}{ Anemia } & $\underset{(n=42)}{S T}$ & & \\
\hline & & $\begin{array}{c}\mathrm{ST}+\mathrm{HBO} \\
(\mathrm{n}=46)\end{array}$ & $7.3 \pm 0.7 *$ & $8.0 \pm 0.5$ \\
\hline & \multirow{2}{*}{$\mathrm{AH}$} & $\begin{array}{c}\mathrm{ST} \\
(\mathrm{n}=25)\end{array}$ & $7.1 \pm 0.7 *$ & $7.7 \pm 0.5^{*}$ \\
\hline & & $\begin{array}{c}\mathrm{ST}+\mathrm{HBO} \\
(\mathrm{n}=25)\end{array}$ & $7.5 \pm 0.7 *$ & $7.7 \pm 0.5^{*}$ \\
\hline & \multirow[t]{2}{*}{$\mathrm{ChP}$} & $\begin{array}{c}\mathrm{ST}( \\
\mathrm{n}=26)\end{array}$ & $6.7 \pm 1.0^{*}$ & $7.2 \pm 0.8^{*}$ \\
\hline & & $\begin{array}{c}\mathrm{ST}+\mathrm{HBO} \\
(\mathrm{n}=27)\end{array}$ & $7.5 \pm 0.7 * / * *$ & $7.9 \pm 0.5^{* *}$ \\
\hline \multicolumn{3}{|c|}{ Control group $(n=44)$} & $8.2 \pm 0.7$ & $8.8 \pm 0.5$ \\
\hline \multicolumn{3}{|c|}{ Total $(n=235)$} & $7.3 \pm 0.7$ & $7.8 \pm 0.7$ \\
\hline
\end{tabular}

* - $P<0.05$ vs. the control group; ** $P<0.05$ - between subgroups depending on on the nature of the therapy

Analysis of neonatal morbidity showed that this indicator was $654.4 \%$ in newborns born to mothers with EGDs, while in cases of the control group it was $68 \%$ (Fig. 1 ).



Fig. 1. Neonatal morbidity (\%) in studied groups.

Conjunctional jaundice was diagnosed in $30.7 \%$ of newborns of the subgroup Ia, which was significantly more 
frequent compared to the control (0) and subgroups Ic (15.1\%) and $\mathrm{Ib}(8 \%)$.

RDS was significantly more often $(22.6 \%)$ diagnosed in neoborns of subgroup Ic $(22.6 \%)$ compared to the control and subgroups Ia $(11.4 \%)$ and $\mathrm{Ib}(8 \%), \mathrm{P}<0.05$ in all cases. Congenital pneumonia was recorded in $16.9 \%$ of newborns born to mothers of subgroup IC, which was significantly more often than in subgroups Ia (5.7\%) and $\mathrm{Ib}(4 \%), \mathrm{P}<0.05$ in all cases.

HIBI was significantly higher among all newborns in the main group compared to the newborns born to mothers of the control group $(\mathrm{P}<0.05)$. HIBI frequency in subgroups Ia and $\mathrm{Ib}$ was $26.1 \%$ and $24 \%$, respectively; it was $16.9 \%$ in subgroup Ic, which was significantly more often compared to the control group $(\mathrm{P}<0.05)$, but significantly less often compared to the subgroup Ia $(\mathrm{P}<0.05)$. HIBI was diagnosed in every third newborn born to mothers of subgroups Ia and Ib who received only ST ( $35.7 \%$ and $32 \%$, respectively), and in $23.1 \%$ of newborns born to mothers of subgroup Ic who received only ST. The inclusion of HBO in complex therapy contributed to a 2 -fold $(\mathrm{P}<0.05)$ decrease in HIBI frequency.

In order to assess the effectiveness of HBO in a complex of therapeutic and prophylactic measures in pregnant women with high PR, a comparative analysis of neonatal morbidity was performed (Table 5).

\section{Table 5.}

Neonatal morbidity depending on the nature of the therapy.

\begin{tabular}{|c|c|c|c|c|c|c|}
\hline \multicolumn{3}{|c|}{$\begin{array}{l}\text { Group/ } \\
\text { Subgroup }\end{array}$} & \multirow{2}{*}{ 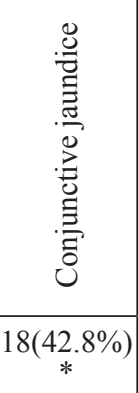 } & \multirow{2}{*}{$\begin{array}{c}\overrightarrow{\underline{9}} \\
\qquad \begin{array}{c}(35.7 \%) \\
*\end{array}\end{array}$} & \multirow{2}{*}{$\begin{array}{c}\text { ลิ } \\
\begin{array}{c}8(19.0 \%) \\
*\end{array}\end{array}$} & \multirow{2}{*}{ 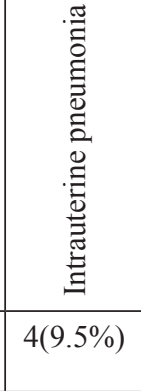 } \\
\hline \multirow{6}{*}{ 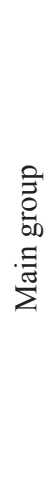 } & \multirow{2}{*}{ Anemia } & $\underset{(n=42)}{\mathrm{ST}}$ & & & & \\
\hline & & $\begin{array}{c}\mathrm{ST}+\mathrm{HBO} \\
(\mathrm{n}=46)\end{array}$ & $\begin{array}{c}9(19.6 \%) \\
* / * *\end{array}$ & $\begin{array}{c}8(17.4 \%) \\
* / * *\end{array}$ & $\begin{array}{c}2(4.3 \%) \\
* *\end{array}$ & $1(2.2 \%)$ \\
\hline & \multirow{2}{*}{$\mathrm{AH}$} & $\begin{array}{c}\text { ST } \\
(\mathrm{n}=25)\end{array}$ & $3(12.0 \%)$ & $\begin{array}{c}8(32.0 \%) \\
*\end{array}$ & $3(12.0 \%)$ & $3(12.0 \%)^{*}$ \\
\hline & & $\begin{array}{c}\mathrm{ST}+\mathrm{HBO} \\
(\mathrm{n}=25)\end{array}$ & $1(4.0 \%)$ & $4(16.0 \%)$ & $1(4.0 \%)$ & $1(4.0 \%)^{* *}$ \\
\hline & \multirow{2}{*}{$\mathrm{ChP}$} & $\begin{array}{c}\text { ST } \\
(n=26)\end{array}$ & $\begin{array}{c}6(23.1 \%) \\
*\end{array}$ & $\begin{array}{c}6(23.1 \%) \\
*\end{array}$ & $\begin{array}{c}9(34.6 \%) \\
* / * *\end{array}$ & $7(26.9 \%)^{*}$ \\
\hline & & $\begin{array}{c}\mathrm{ST}+\mathrm{HBO} \\
(\mathrm{n}=27)\end{array}$ & $\underset{* *}{2(7.4 \%)}$ & $3(11.1 \%)$ & $3(11.1 \%)$ & $2(7.4 \%)^{* *}$ \\
\hline \multicolumn{3}{|c|}{$\begin{array}{l}\text { Control } \\
\text { group }(n=44)\end{array}$} & 0 & $2(4.5 \%)$ & $1(2.3 \%)$ & 0 \\
\hline \multicolumn{3}{|c|}{$\begin{array}{l}\text { Total } \\
(n=235)\end{array}$} & $39(16.5 \%)$ & $46(19.5 \%)$ & $27(11.4 \%)$ & $18(7.6 \%)$ \\
\hline
\end{tabular}

* - $P<0.05$ vs. the control group; ** $P<0.05$ - between subgroups depending on on the nature of the therapy

Data obtained showed that conjunctive jaundice was significantly less frequent in newborns whose mothers received HBO: 2.2 times for subgroup Ia, 3 times for subgroup $\mathrm{Ib}$, and 3.1 times for subgroup Ic. Intrauterine pneumonia was more often diagnosed in newborns of the subgroup Ic mothers: $26.9 \%$ against $\mathrm{ST}$, and $7.4 \%$ against $\mathrm{ST}+\mathrm{HBO}$ (a 3.6-fold decrease) $(\mathrm{P}<0.05)$. The inclusion of HBO in complex therapy also contributed to a significant decrease $(\mathrm{P}<0.05)$ in RDS frequency: 4.4 times for subgroup IA, 3.1 times for subgroup IC, and 3 times for subgroup IB.

Obviously, a decrease in the frequency of PL in the subgroups of pregnant women in the main group who received $\mathrm{ST}+\mathrm{HBO}$ promoted a statistically significant reduction in neonatal morbidity.

\section{Conclusion}

The inclusion of HBO in a complex of therapeutic and prophylactic measures in pregnant women with high PR contributed to a significant decrease in all subgroups:

\section{In subgroup Ia:}

- Threatened late SMs from $19.0 \%$ to $8.7 \%$;

- Threatened PL from $33.3 \%$ to $19.6 \%$;

- Preeclampsia from $30.9 \%$ to $17.4 \%$;

- Preterm birth from $26.2 \%$ to $8.7 \%$;

- LBWN from $26.2 \%$ to $13.0 \%$.

\section{In subgroup Ib:}

- Threatened late SMs from $20.0 \%$ to $12.0 \%$;

- Threatened PL from $32.0 \%$ to $16.0 \%$;

- Preeclampsia from $48.0 \%$ to $28.0 \%$;

- Preterm birth from $20.0 \%$ to $12.0 \%$;

- LBWN from $20.0 \%$ to $12.0 \%$.

\section{In subgroup Ic:}

- Threatened late SMs from $34.6 \%$ to $14.8 \%$;

- Threatened PL from $69.2 \%$ to $37.0 \%$;

- Preterm birth from $42.3 \%$ to $18.5 \%$;

- LBWN from $23.1 \%$ to $11.1 \%$.

A significant decrease in the incidence of LBWN in pregnant women with EGD who received ST+HBO contributed to a statistically significant improvement in neonatal morbidity parameters. The rate of neonatal morbidity significantly decreased in patients with anemia, GhP, and $\mathrm{AH}$ from 1071\% to $435 \%$, from $1077 \%$ o to $370.4 \%$, and from $1080 \%$ to $280 \%$, respectively.

\section{Competing interests}

The authors declare that they have no competing interests.

\section{References}

1. Radzinsky VE. Obstetric aggression. M.: StatusPraesens; 2011, 668 pp. [in Russian].

2. Federal State Statistics Service. Rosstat. [Electronic resource]. http://www.gks.ru (reference date: September 15, 2015). 
3. Shuvalova MP, Frolova OG, Grebennik TK., Ratushnyak SS, Guseva EV. Extragenital diseases as a cause of maternal death. Akusherstvo I Cinekologiya. 2015;1:104-110. [Article in Russian].

4. In Radzinsky VE, Orazmuradov AA, editors. Early gestational age. 2nd ed., rev. version. - M.: StatusPraesens; 2009, 480 pp. [in Russian]

5. Radzinsky VE, Knyazev CA, IN Kostin. Obstetric risk.
Maximum of information - Mminimum of danger to the mother and baby. M.: Eksmo; 2009, 290 pp. [in Russian].

6. Baidina SA, Gramenitskiy AB, Rubinchik BA. Manual of hyperbaric medicine. M: Medicine, 2008. [in Russian].

7. Orasmuradov AA, Paendi OL, Paendi FA. Modern possibilities of hyperbaric oxygen therapy in pregnant women with anemia. International Journal of Biomedicine. 2014;4(2):82-4 